\title{
Practical Factors Controlling in vitro Multiplication and Rooting in Empetrum nigrum var. japonicum, an Endangered Woody Species
}

\author{
So-Young Park ${ }^{1}$, Yong-Wook Kim ${ }^{2}$ and Heung-Kyu Moon ${ }^{2} *$ \\ ${ }^{1}$ Department of Horticultural Science, Chungbuk National University, Cheongju 361-763, Korea \\ ${ }^{2}$ Division of Forest Biotechnology, Korea Forest Research Institute, Suwon 441-847, Korea
}

\begin{abstract}
The plant Empetrum nigrum, valued in the traditional system of medicine, is well known for its antibacterial, antifungal, and antioxidant properties. In the present work, the effect of removal of shoot apical meristem (SAM) on shoot proliferation was studied. It was observed that removal of SAM promoted shoot proliferation whereas intact tip resulted in higher survival percentage. Further, the effect of different concentrations of BA on above was also studied. During root formation the effect of light quality after treatment with IBA was investigated. For rooting, continuous red light without IBA resulted in maximum rooting percentage. The above factors when taken into consideration during micropropagation of this endangered plant can result in healthier plantlets. The results show that the species could be successfully conserved by in vitro propagation system.
\end{abstract}

Key words - Empetrum nigrum, Micropropagation, SAM, Shoot tip removal, Red light

\section{Introduction}

Empetrum nigrum var. japonicum (crowberry), a medicinal woody plant belongs to Ericaceae family, is one of the native berries of South Korea, especially on top of Mt. Halla (Han et al., 2010). Empetrum is a small genus of dwarf $(10-30 \mathrm{~cm}$ in height) evergreen shrubs. The leaves and stems are used in Denaina medicine for diarrhea and stomach problems; they are boiled or soaked in hot water, and the strained liquid is consumed. Its extract exhibits diuretic and spasmolytic properties, aerial parts used in folk medicine to cure liver and kidney disease (Krasnov et al., 2000), certain components show antibacterial and fungicidal activity (McCutcheon et al., 1994). Several reports have indicated the antioxidant potential of this plant (Kahkonen et al., 1999; Kim et al., 2009; Kim et al., 2011). Although the E. nigrum var. japonicum is important as a medicinal material and one of Korean genetic resources, few reports have been focused on in vitro micropropagation of the species except the report by Han et al. (2010). Herein, we report the results for in vitro shoot multiplication and rooting of rooting-recalcitrant $E$.

*Corresponding author. E-mail : hkmoon@forest.go.kr nigrum and it show that the possibility of improving the shoot proliferation by removing SAM and rooting by red light irradiation.

\section{Materials and Methods}

\section{Plant materials}

Two years in vitro maintained Empetrum nigrum var. japonicum in hormone-free Woody plant medium (WPM; Lloyd and McCown, 1981) medium were used for the experiments. For rooting, $2 \mathrm{~cm}$-length of shoots were used.

\section{Shoot multiplication}

For shoot proliferation, two types of plant material were used, shoot with intact apical meristem (ST) and shoot without apical meristem (N-ST). In both the BA concentration were varied as $0.2,0.5,1.0 \mathrm{mg} / \mathrm{L}$ with WPM as the basal medium.

\section{Rooting}

For rooting two sets of shoots were used. In one set the bottom of shoot was soaked into $1,000 \mathrm{mg} / \mathrm{L}$ IBA for $30 \mathrm{~min}$, after that placed into hormone-free WPM containing sucrose 
$30 \mathrm{~g} / \mathrm{L}$ and solidified with $2.5 \mathrm{~g} / \mathrm{L}$ gelrite. The other set of shoots did not receive the IBA treatment. Thereafter both these sets of shoots received light treatments as indicated in Table 1.

For red irradiation, LED system (GF-320s) with, peak emission at $650 \mathrm{~nm}$ was used and fluorescent lamp was used for white light. The light intensity in all kinds of light treatment was $40 \mu \mathrm{mol} \mathrm{m}^{-2} \mathrm{~s}^{-1} \mathrm{PPF}$. All the cultures were kept at $23 \pm 1{ }^{\circ} \mathrm{C}$ with $16 / 8-\mathrm{hr}$ (day/night) photoperiod and cultured for 8 weeks.

\section{Statistics}

All experiments were repeated three times with ten replications. Statistical significance was determined using Duncan's multiple range test $(\mathrm{p} \leq 0.05)$ for a multi-comparison of means (SAS Institute, Cary, N.C.). Values marked with similar letters are not significantly different.

\section{Results and Discussion}

As previous report (Han et al., 2010) had shown that WPM medium was found to be the best medium for growth of Empetrum nigrum var. japonicum, in the present study it was used for shoot multiplication in combination with different concentrations of BA. It was observed that increasing BA concentration did not have any significant effect on shoot survival or proliferation. Further, the effect of removal of shoot apical meristem (SAM) from the explants was also studied. The SAM consists of a small group of undifferentiated and dividing cells with dense cytoplasm. Potten and Loeffler (1990) on the basis of several criteria suggested that the cells in the meristem can be classified as stem cells. These cells have the unique abilities to proliferate, to replace themselves when required, to give rise to a variety of differentiated cell types, and also can regenerate a new meristem if damaged (Sussex, 1952). Also, Reddy et al. (2004) reported that these

Table 1. Effect of apical meristem elimination from shoot explants on shoot multiplication from in vitro grown Empetrum nigrum var. japonicum after 8 weeks of culture

\begin{tabular}{crccc}
\hline \hline \multirow{2}{*}{ BA $(\mathrm{mg} / \mathrm{L})$} & \multicolumn{2}{c}{ Survival rate (\%) } & \multicolumn{2}{c}{ No of shoots (per explant) } \\
\cline { 2 - 5 } & \multicolumn{1}{c}{ ST } & N-ST & ST & N-ST \\
\hline 0.0 & 93.3 & 83.3 & $1.0 \pm 0.09$ & $2.7 \pm 0.6$ \\
0.2 & 100.0 & 93.5 & $1.0 \pm 0.10$ & $2.8 \pm 0.5$ \\
0.5 & 100.0 & 93.3 & $1.0 \pm 0.21$ & $3.0 \pm 0.4$ \\
1.0 & 100.0 & 92.1 & $1.0 \pm 0.13$ & $3.0 \pm 0.4$ \\
\hline
\end{tabular}

${ }^{\mathrm{ST}}$ Normal shoot with apical meristem

${ }^{\mathrm{N}-\mathrm{ST}}$ Apical meristem eliminated-shoot
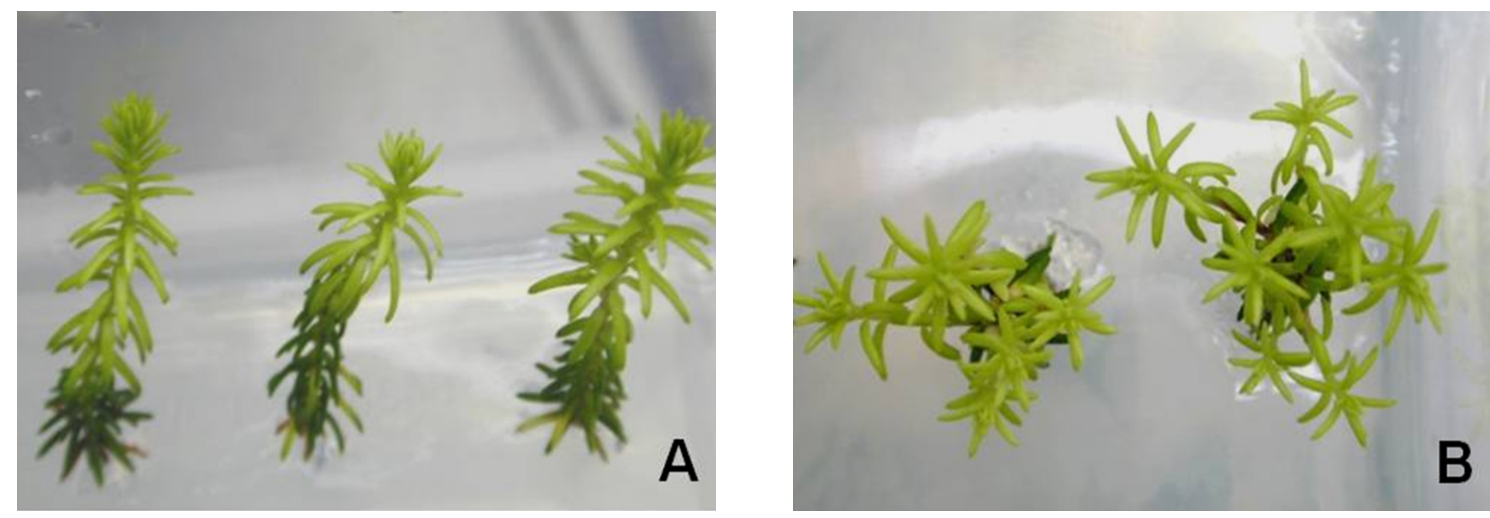

Fig. 1. Shoot multiplication from different type of explants after 8 weeks of culture in Empetrum nigrum var. japonicum. A: Normal shoots with apical meristem, B: Apical meristem eliminated-shoot. 
stem cells are responsible for initiation of lateral organs. In case of Empetrum nigrum var. japonicum, it was found that explants without SAM had a lower survival percentage (Table 1). Barton and Poethig (1993) while working on shoot apical meristem fewer mutants of Arabidopsis observed that conditions that promote shoot regeneration in vitro in the wild type could not result in normal shoot formation in the explants of mutant type. The latter only gave rise to abnormal leaves or shoots but its number was lesser than in wild type. They suggested that the gene stm-1 interferes with shoot formation in vitro but an organized SAM is not required for leaf and shoot formation both in culture and in situ (Barton and Poethig, 1993). Our results also indicate that in Empetrum presence of SAM is not essential for shoot formation in vitro (Fig. 1). In fact removal of shoot tip in the present genus resulted in higher shoot proliferation by suppression of apical dominance.

During rooting it was observed that in the absence of IBA highest rooting percentage was observed in shoots kept in continuous red light (39\%) followed by shoots kept under continuous light for eight weeks (Fig. 2). This indicates that red light alone is sufficient for root development in Empetrum. Possibly other wavelengths of light exert a negative effect on root formation in this genus as rooting percentage reduced to

Table 2. Description of light and hormonal treatments for rooting in E. nigrum var. japonicum

\begin{tabular}{|c|c|c|c|c|c|c|c|c|c|}
\hline \multirow{2}{*}{ Treatment } & \multirow{2}{*}{ IBA } & \multicolumn{8}{|c|}{ Week } \\
\hline & & 1 & 2 & 3 & 4 & 5 & 6 & 7 & 8 \\
\hline \multicolumn{10}{|l|}{ E1: Light effect } \\
\hline CL (Continuous light) & - & $\mathrm{L}$ & $\mathrm{L}$ & $\mathrm{L}$ & $\mathrm{L}$ & $\mathrm{L}$ & $\mathrm{L}$ & $\mathrm{L}$ & $\mathrm{L}$ \\
\hline DL (Dark $\rightarrow$ light) & - & $\mathrm{D}$ & $\mathrm{D}$ & $\mathrm{L}$ & $\mathrm{L}$ & $\mathrm{L}$ & $\mathrm{L}$ & $\mathrm{L}$ & $\mathrm{L}$ \\
\hline $\mathrm{RL}^{\mathrm{z}}($ Red $\rightarrow$ light $)$ & - & $\mathrm{R}$ & $\mathrm{R}$ & $\mathrm{L}$ & $\mathrm{L}$ & $\mathrm{L}$ & $\mathrm{L}$ & $\mathrm{L}$ & $\mathrm{L}$ \\
\hline CR (Continuous red) & - & $\mathrm{R}$ & $\mathrm{R}$ & $\mathrm{R}$ & $\mathrm{R}$ & $\mathrm{R}$ & $\mathrm{R}$ & $\mathrm{R}$ & $\mathrm{R}$ \\
\hline \multicolumn{10}{|c|}{ E2: Light \& IBA effect } \\
\hline CL (Continuous light) & - & $\mathrm{L}$ & $\mathrm{L}$ & $\mathrm{L}$ & $\mathrm{L}$ & $\mathrm{L}$ & $\mathrm{L}$ & $\mathrm{L}$ & $\mathrm{L}$ \\
\hline $\mathrm{IL}^{\mathrm{y}}$ (IBA + light $)$ & $\mathrm{O}$ & $\mathrm{L}$ & $\mathrm{L}$ & $\mathrm{L}$ & $\mathrm{L}$ & $\mathrm{L}$ & $\mathrm{L}$ & $\mathrm{L}$ & $\mathrm{L}$ \\
\hline IRL $($ IBA+red $\rightarrow$ light $)$ & $\mathrm{O}$ & $\mathrm{R}$ & $\mathrm{R}$ & $\mathrm{L}$ & $\mathrm{L}$ & $\mathrm{L}$ & $\mathrm{L}$ & $\mathrm{L}$ & $\mathrm{L}$ \\
\hline
\end{tabular}

${ }^{\mathrm{z}}$ Red irradiation : LED system (GF-320s), peak emission : $650 \mathrm{~nm}$.

${ }^{\mathrm{y}}$ IBA treatment: Immersion into IBA $1,000 \mathrm{mg} \mathrm{L}-1$ solution for $30 \mathrm{~min}$.

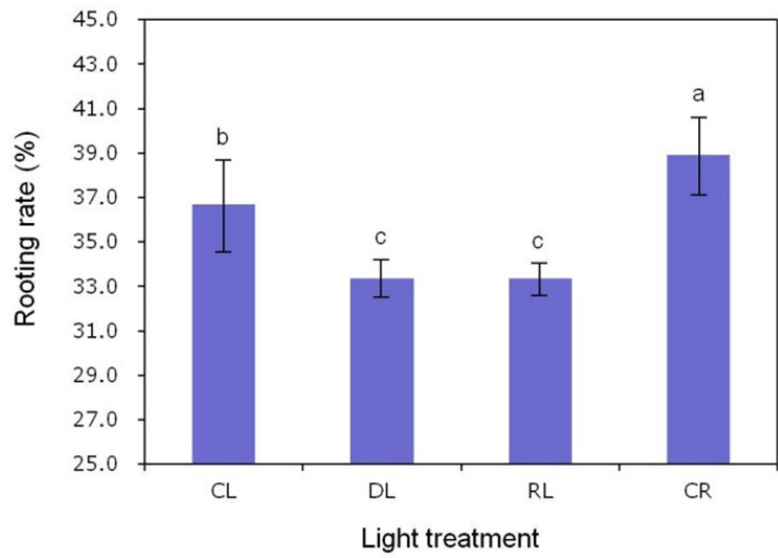

(A)

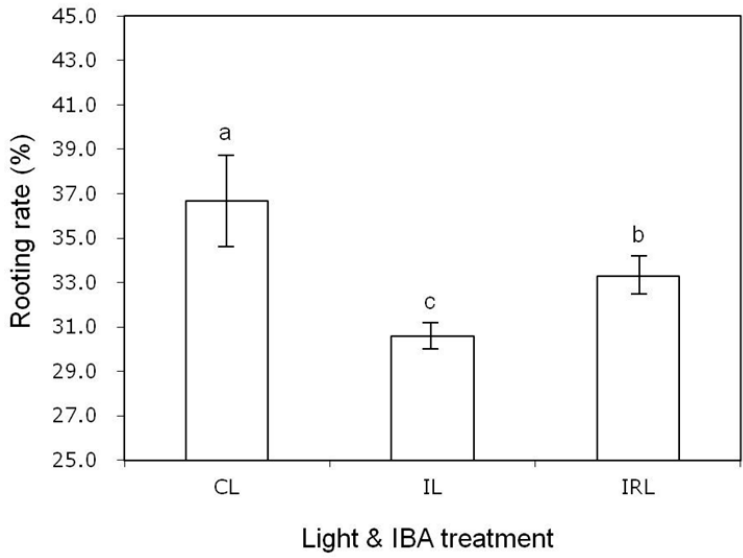

(B)

Fig. 2. Effect of light (A) and IBA treatment (B) on rooting from in vitro shoots of E. nigrum var. japonicum. (Error bars represent for standard errors of mean, and the letter on the error bars represent for significance by Duncan's multiple range test, $\mathrm{p} \leq 0.05$ ). 
$37 \%$ in white light. Further, it was also seen that providing red light for only first two weeks followed by continuous white light resulted in poor rooting. Taiz and Zeiger (1991) reported that growth and development in plants is influenced by the quality, intensity and duration of light. Similarly, growth, morphology and differentiation of in vitro plantlets are also affected by light (Economou and Read, 1987). Red light has been shown to significantly enhance stem elongation in Pelargonium plantlets (Appelgren, 1991); higher root to shoot ratio in potato plantlets (Aksenova et al., 1994) and affect morphology rather than growth of potato plantlets when used as main light source (Miyashita et al., 1995).

However, in the present study when the shoots are pretreated with IBA, root formation was considerably reduced (31\%) even in presence of continuous light (Fig. 2). When after IBA treatment, the shoots were kept in red light for two weeks and then transferred to white light, the rooting percentage improved a little (33\%). Any plant under normal environmental conditions can proceed via either of two developmental pathways: photomorphogenesis in the light and skotomorphogenesis in the dark (von Arnim and Deng, 1996). The choice that a plant makes between these two pathways is crucial for its development and also ensures survival in its environment. To select the appropriate pathway, plants possess several photoreceptors to detect the different qualities and quantities of light (Fankhauser and Chory, 1997). Several physiological experiments have indicated that auxin is the major plant hormone closely connected with light signal transduction (Neff et al., 1999; Steindler et al., 1999). In addition to hypocotyl elongation, auxin affects numerous aspects of plant growth and development such as gravitropism, lateral root differentiation and apical dominance (Estelle and Klee, 1994; Hobbie, 1998). Auxin has different effects on different tissues: it stimulates cell elongation in stems and hypocotyls, whereas in roots it stimulates cell division for lateral root formation (Estelle and Klee, 1994; Hobbie, 1998). However, in Empetrum auxin pre-treatment for $30 \mathrm{~min}$ has a negative influence on rooting. This is similar to the findings of Nakazawa et al. (2001) in Arabidopsis. They observed that the gene product of DFL1 gene (an auxin responsive gene) in Arabidopsis inhibits
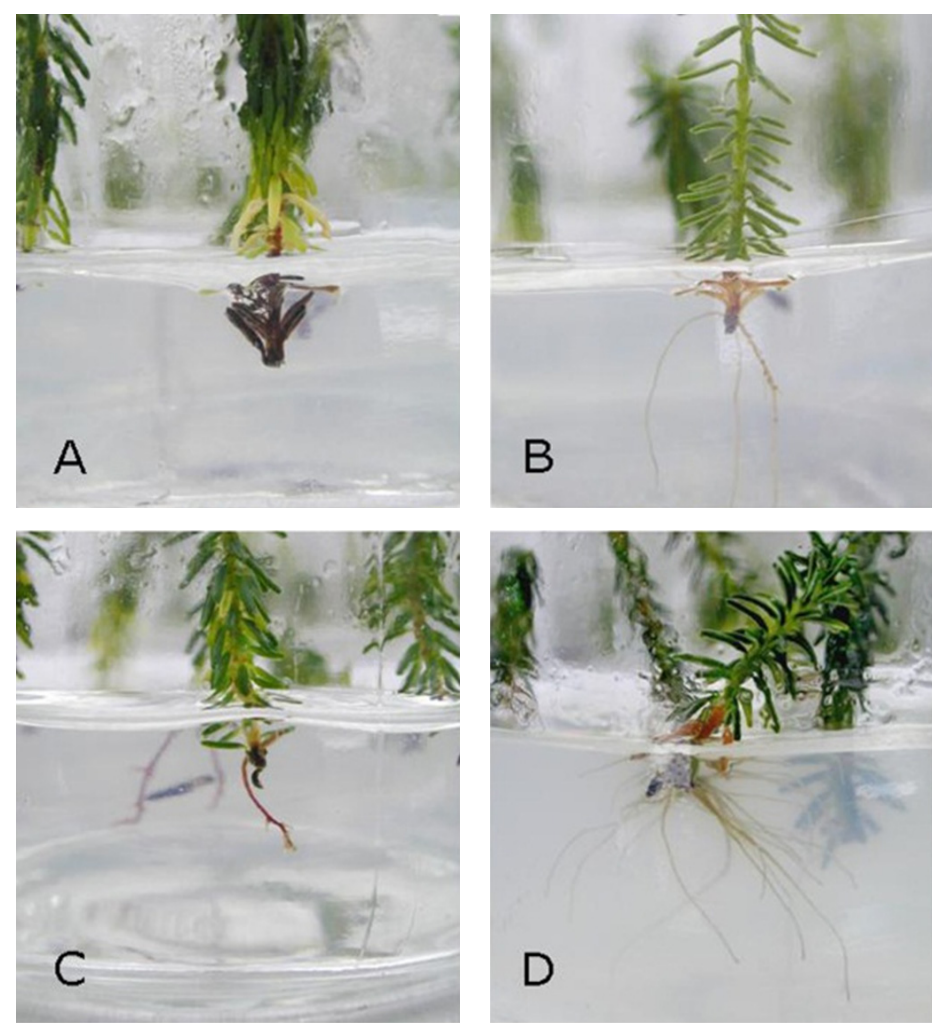

Fig. 3. Effect of light quality on rooting in E. nigrum var. japonicum after 8 weeks of culture. A: IBA + light (IL), B: IBA + red to light (IRL), C: Dark to light (DL), D: Continuous red irradiation. 
lateral root cell differentiation in light though it has no effect on primary root formation. Since the lateral roots emerge from the primary root by a series of divisions in the pericycle cells (Malamy and Benfey, 1997) probably in Empetrum auxin exposure has a negative effect on this activity. The positive effect of red light is seen even in presence of IBA indicating that in this genus the quality of light can overcome the inhibition by auxin.

Thus the present study indicates that SAM and light quality can affect in vitro propagation of Empetrum nigrum var. japonicum. This information can be used for increasing the efficiency of micropropagation of this endangered medicinal plant.

\section{Acknowledgement}

This work was supported by the research grants of the Korean Forest Research Institute and Chungbuk National University in 2012.

\section{Literature Cited}

Appelgren, M. 1991. Effects of light quality on stem elongation of Pelargonium in vitro. Scientia Hort. 45:345-351.

Aksenova, N.P., T.N. Konstantinova, L.I. Sergeeva, I. Machackova and S.A. Golyanovskaya. 1994. Morphogenesis of potato plants in vitro. I. Effect of light quality and hormones. J. Plant Growth Regul. 13:143-146.

Barton, M.K. and R. S. Poethig. 1993. Formation of the shoot apical meristem in Arabidopsis thaliana: an analysis of development in the wild type and in the shoot meristemless mutant. Development 119:823-83.

Economou, A.S. and P.E. Read. 1987. Light treatments to improve efficiency of in vitro propagation systems. Hort. Sci. 22:751-754.

Estelle, M. and H.J. Klee. 1994. Auxin and cytokinin in Arabidopsis. In Meyeowitz E.M. and C.R. Somerville (eds.), Arabidopsis, Cold Spring Harbor: Cold Spring Harbor Laboratory Press, New York, USA. pp. 555-578.

Fankhauser, C. and J. Chory. 1997. Light control of plant development. Annu. Rev. Cell. Dev. Biol. 13:203-229.

Han, M.S., S.Y. Park, H.K. Moon and Y.J. Kang. 2010. Micropropagation of a rare tree species, Empetrum nigrum var. japonicum K. Koch via axillary bud culture. Jour. Korean For. Soc. 99:568-572.

Hobbie, L.J. 1998. Auxin: molecular genetic approaches in Arabidopsis. Plant Physiol. Biochem. 36:91-102.

Kahkonen, M.P., A.I. Hopia, H.J. Vuorela, J.P. Rauha, K. Pihlaja, T.S. Kujala and M. Heinonen. 1999. Antioxidant activity of plant extracts containing phenolic compounds. J. Agric. Food Chem. 47:3954-3962.

Kim, K.C., I.K. Lee, K.A. Kang, B.J. Kim, D. Kim, J.Y. Moon, B.S. Yoo and J.W. Hyun. 2011. Empetrum nigrum var. japonicum extract suppresses $\gamma$-ray radiation-induced cell damage via inhibition of oxidative stress. Am. J. Chin. Med. 39:161-170.

Kim, K.C., K.A. Kang, R. Zhang, M.J. Piao, Y.J. Heo, S. Chae, G.Y. Kim, J.Y. Moon, B.S. Yoo and J.W. Hyun. 2009. Risk reduction of ethyl acetate fraction of Empetrum nigrum var. japonicum via antioxidant properties against hydrogen peroxide-induced cell damage. J. Toxicol. Environ. Health. 72:1499-1508

Krasnov, E.A., E.V. Ermilova, T.V. Kadyrova, V.A. Raldugin, I. Yu. Bagryanskaya, Yu. V. Gatilov, A.G. Druganov, A.A. Semenov and G.A. Tolstikov. 2000. Phenolic components of Empetrum nigrum extract and the crystal structure of one of them. Chem. Nat. Comp. 36:493-496.

Lloyd, G. and B. McCown. 1981. Commercially-feasible micropropagation of mountain laurel, Kalmia latifolia, by use of shoot tip culture. Proc. Int. Plant Propagators Soc. 30:421-427.

Malamy, J.E. and P.N. Benfey. 1997. Organization and cell differentiation in lateral roots of Arabidopsis thaliana. Development 124:33-44.

McCutcheon, A.R., S.M. Ellis, R.E.W. Hancock and G.H.N. Towers. 1994. Antifungal screening of medicinal plants of British Columbian native people. J. Ethnopharmacology. 44:157-169.

Miyashita, Y., T. Kimura, Y. Kitaya and T. Kozai. 1995. Effects of red light on growth and morphology of potato plantlets in vitro: Using LEDs as light source for micropropagation. Acta Hort. 418:169-173.

Nakazawa, M., N. Yabe, T. Ichikawa, Y.Y. Yamamoto, T. Yoshizumi, K. Hasunuma and M. Matsui. 2001. DFL1, an auxin-responsive GH3 gene homologue, negatively regulates shoot cell elongation and lateral root formation, and positively regulates the light response of hypocotyls length. Plant J. 25:213-221. 
Neff, M.M., S.M. Nguyen and E.J Malancharuvil. 1999. BAS1: a gene regulating brassinosteroid levels and light responsiveness in Arabidopsis. Proc. Natl. Acad. Sci. USA. 96:15316-15323.

Potten, C.S. and M. Loeffler. 1990. Stem cells: attributes, cycles, spirals, pitfalls and uncertainties. Lessons for and from the crypt. Development 110:1001-1020.

Reddy, G.V., M.G. Heisler, D.W. Ehrhardt and E.M. Meyerowitz. 2004. Real-time lineage analysis reveals oriented cell divisions associated with morphogenesis at the shoot apex of Arabidopsis thaliana. Development 131:4225-4237.

Steindler, C., A. Matteucci, G. Sessa, T. Weimar, M. Ohgishi,
T. Aoyama, G. Morelli and I. Ruberti. 1999. Shade avoidance responses are mediated by the ATHB-2 HD-Zip protein, a negative regulator of gene expression. Development 126:4235-4245.

Sussex, I. M. 1952. Regeneration of the potato shoot apex. Nature 170:224-225.

Taiz, L. and E. Zeiger.1991. Plant Physiology. $1^{\text {st }}$ ed. Benjamin/ Cummings Publ. Co. New York, USA. pp. 179-264.

von Arnim, A. and X.W. Deng. 1996. Light control of seeding development. Annu. Rev. Plant Physiol. Plant Mol. Biol. 47:215-243.

(Received 10 October 2012 ; Revised 6 December 2012 ; Accepted 14 December 2012) 